\title{
Demonstration of oestrogen receptors in paraffin wax sections of breast carcinoma using the monoclonal antibody 1D5 and microwave oven processing
}

\author{
P Sannino, S Shousha
}

\begin{abstract}
This study aimed at assessing the usefulness of a new monoclonal antibody (1D5) for the demonstration of oestrogen receptors (ER) in paraffin wax sections, using brief microwave processing rather than proteolytic predigestion. Routinely processed paraffin wax sections of 50 cases of breast carcinoma with known ER concentrations, estimated by the standard dextran-coated charcoal (DCC) biochemical assay, were examined using the avidin-biotin complex-immunoperoxidase technique. The results were assessed semiquantitatively, using a five grade scoring system. Of the 50 cases examined, 37 were positive and six were negative by both DCC and immunohistology. Of the remaining seven cases, three (6\%) were negative by DCC but positive with immunohistology, and four (8\%) were positive with DCC and negative with immunohistology. The DCC results of the latter four cases were 10 , 14,14 and $16 \mathrm{fmol} / \mathrm{mg}$ protein which is at the lowest level of positivity, our cutoff point being less than 10 fmol.

The monoclonal antibody 1D5, as used in this study, can provide easily assessed reliable information about the ER status of breast carcinoma using routinely processed paraffin wax sections.
\end{abstract}

(F Clin Pathol 1994;47:90-92)

The receptor status of a breast tumour is often taken into consideration when planning treatment nowadays. ${ }^{1}$ As biochemical receptor assays are not always available for all tumours, histopathologists are now increasingly asked to provide a service for the assessment of the receptor status in tissue sections. Until recently, only the widely used antibody for the immunohistological demonstration of oestrogen receptors (ER) in tissue sections (ER-ICA, Abbott Laboratories) was recommended by the manufacturers for use in frozen sections. Several modifications to the original technique, however, have been developed to allow for the use of paraffin wax rather than frozen sections. ${ }^{23}$ These modifications require proteolytic enzyme digestion of the sections before starting the staining procedure, and this sometimes can affect the quality of sections.

We describe here our experience with a new monoclonal antibody (1D5, Dako Ltd,
UK), for the demonstration of ER in paraffin wax sections. The antibody does not require proteolytic predigestion, although it does need a brief period of processing in a microwave oven. We also compared the results obtained with this technique in three cases with those obtained with the same antibody using frozen sections, and with those obtained with Abbott's antibody using frozen and paraffin wax sections.

\section{Methods}

The study was carried out on 50 cases of breast carcinoma with known ER concentrations, estimated by the standard dextrancoated charcoal (DCC) biochemical assay. All cases had been fixed in formalin and embedded in paraffin wax. Four micrometer thick sections were cut, mounted on APES (Sigma) treated slides, and left to dry overnight at $37^{\circ} \mathrm{C}$. On the following day, sections were dewaxed in xylene for five minutes and rehydrated in graded alcohol. Sections were then placed in $10 \mathrm{mM}$ citrate buffer, $\mathrm{pH} 6.0$; microwaved twice, five minutes each, using a microwave oven at full power (650W); left to cool for 20 minutes; and then rinsed in distilled water. Endogenous peroxidase was blocked using 3\% hydrogen peroxide in distilled water for five minutes. This was followed by rinsing in running tap water, then in TRIS buffered saline (TBS). Normal goat serum, at a dilution of one in five, was applied for 20 minutes and then tipped off. This was followed by applying the primary antibody 1D5 (Dako Ltd, High Wycombe, UK) in a concentration of one in 100 for 60 minutes; rinsing in TBS, applying the secondary antibody, goat anti-mouse/ rabbit, one in 100, for 30 minutes; rinsing in TBS; and applying streptavidin-biotin complex (Dako Duet) for 30 minutes. After rinsing in TBS sections were incubated with $0.05 \%$ diaminobenzidine (Sigma, Poole, UK) in $0.01 \%$ hydrogen peroxide for three minutes; rinsed in tap water; counterstained in Mayer's haematoxylin for 25 seconds; blued in tap water; then dehydrated, cleared, and mounted with ralmount (BDH, Poole, UK).

Stored frozen tissue was available from three out of the 50 cases examined. All three cases were ER positive when assayed with the DCC technique. Frozen sections, $6 \mu \mathrm{m}$ thick, were cut from the three cases and fixed in $4 \%$ buffered formalin for 15 minutes, followed by methanol, at $-20^{\circ} \mathrm{C}$, for five minutes, and then acetone, also at $-20^{\circ} \mathrm{C}$, for three min- 
utes. Sections were then rinsed in TBS and stained with 1D5 antibody as described above, and with Abbott's ER-ICA monoclonal antibody as recommended by the manufacturers. Paraffin wax sections from the same three cases were stained with Abbott's monoclonal antibody ER-ICA using the previously described immunoperoxidase technique. ${ }^{4}$

Attempts were also made, using paraffin wax sections of a known ER positive case and 1D5 antibody, to avoid using the microwave step by incubating the sections overnight with 1D5. Reduced and increased times of microwave exposure were also tried on different sections from the same case.

Negative controls were sections of the cases under examination, treated in the same way except that the specific antibody step was omitted.

Positivity was indicated by the presence of dark brown nuclear staining. The results were assessed semiquantitatively using a five grade scoring system from - to ++++ based on the percentage of stained tumour cells (occasional, less than $\frac{1}{3}$ (score 1); less than $\frac{2}{3}$ (score 2 ); and almost all (score 3), and the intensity of that staining (moderate (score 1) and strong (score 2)). A case was scored as - when no staining was seen in tumour cells; + indicated the presence of an occasional positive cell; ++ (total score 1 ) indicated cases where up to a third of the tumour cells were moderately stained $(1 \times 1) ;+++$ (total score 2-4) indicated strong staining of up to two thirds of the tumour cells $(1 \times 2$ or $2 \times 2)$ or moderate staining in almost all tumour cells $(3 \times 1) ;++++$ (total score 6$)$ was used when almost all the tumour cells were

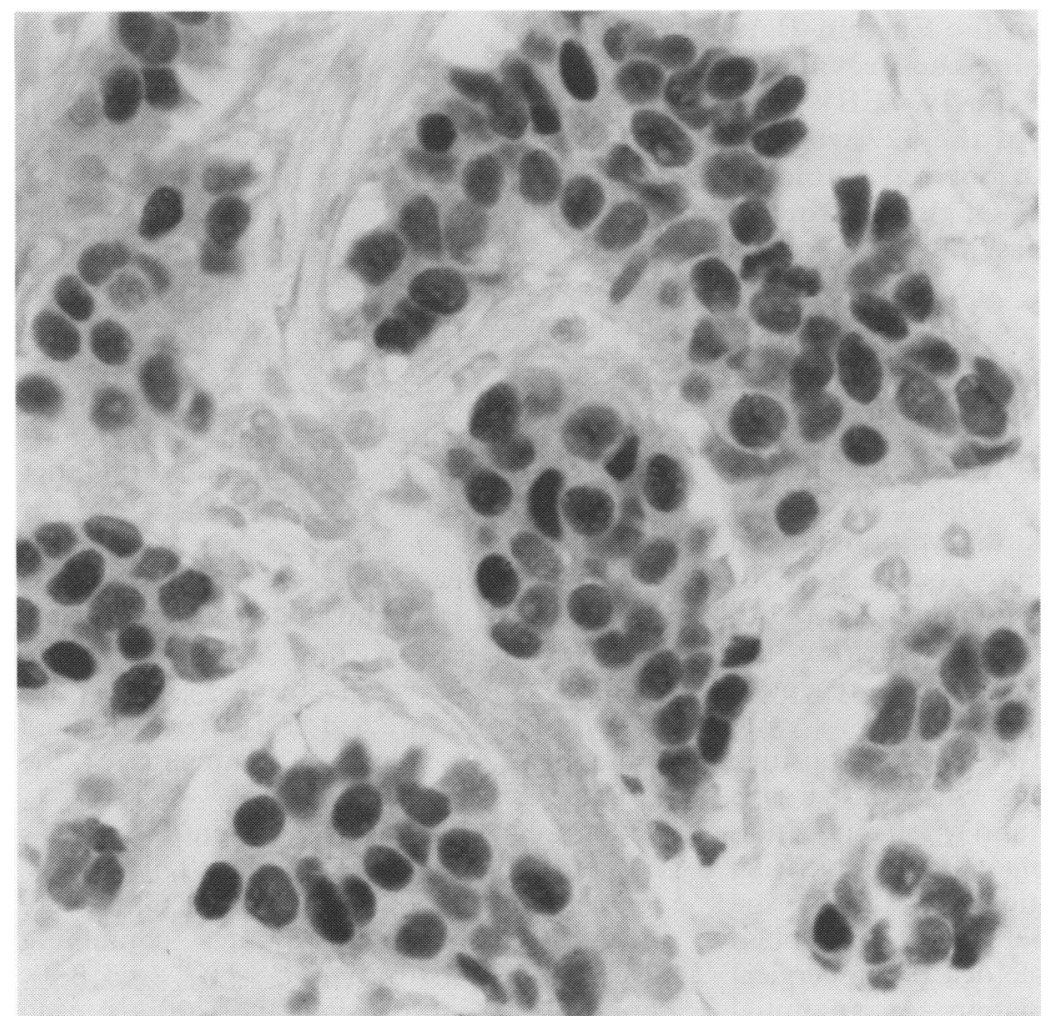

ER positive invasive ductal carcinoma. Immunoperoxidase using $1 D 5$ antibody.
Correlations between immunohistology (IH) score and biochemical (DCC) mean and range values

\begin{tabular}{llcl}
\hline IH score & $\begin{array}{l}\text { Number } \\
\text { of cases }\end{array}$ & $\begin{array}{l}\text { DCC } \\
\text { mean }\end{array}$ & $\begin{array}{l}\text { DCC } \\
\text { range }\end{array}$ \\
\hline- & 10 & 8 & $<10-16$ \\
+ & 6 & 22 & $<10-37$ \\
++ & 4 & 33 & $<10-79$ \\
+++ & 18 & 90 & $<10-332$ \\
++++ & 12 & 365 & $81-922$ \\
\hline
\end{tabular}

strongly stained $(3 \times 2)$. All cases were scored independently by both authors and the results compared.

\section{Results}

Of the 50 cases examined, 37 were positive and six were negative by both DCC and immunohistology (figure). The results of the two techniques were thus similar in $86 \%$ of cases. Of the remaining seven cases, three (6\%) were negative by DCC but positive with immunohistology, and four $(8 \%)$ were positive with DCC and negative with immunohistology. The DCC results of the latter four cases were $10,14,14$ and $16 \mathrm{fmol} / \mathrm{mg}$ protein, the lowest level of positivity, our cutoff point being $<10 \mathrm{fmol}$. If the cutoff point was thus increased to $20 \mathrm{fmol} / \mathrm{mg}$ protein, as is the case in many other centres, the concordance between DCC and immunohistology in our study would rise to $94 \%$.

The scoring results of both authors were almost identical. A difference of opinion occurred only in two cases, which were given a score of ++ by one author and +++ by the other. After discussion a score of +++ was agreed for both cases. Good correlation existed between the immunohistology score and the mean of DCC values for cases with similar score. Thus the DCC mean showed a gradual increase from $8 \mathrm{fmol} / \mathrm{mg}$ protein for immunohistology negative cases to a mean of $365 \mathrm{fmol}$ for ++++ cases (table). No cytoplasmic or background staining was seen, and preservation of tissue was good.

The three ER positive cases examined with four different techniques, 1D5 frozen and paraffin wax sections and ER-ICA frozen and paraffin wax sections, gave essentially similar results. The intensity of staining, however, was stronger with the two antibodies, in frozen sections, and preservation of tissue; hence the clarity of staining was better in the microwave than in the enzyme predigested paraffin wax sections.

Attempts at avoiding the use of the microwave oven or reducing the time of exposure were unsuccessful as they resulted in no staining or substantially reduced staining results. Excessive microwave exposure had deleterious effects on the tissue sections.

\section{Discussion}

This study shows that the monoclonal antibody 1D5 can be used successfully for the demonstration of ER in paraffin wax sections of breast carcinoma, and probably in other 
tissues also. No proteolytic enzyme predigestion of sections is required. This can sometimes affect the quality of the sections. However, a brief period of processing in a microwave oven is needed. This is a critical and essential step which has to be carried out in the precise manner described. The results obtained with 1D5 were more intense, but otherwise comparable with those obtained with ER-ICA antibody when used on paraffin wax sections.

Although the staining results were less intense than those obtained with frozen sections, paraffin wax sections have the obvious advantage of using routinely processed tissue and they provide sections of higher quality which are easier to interpret.

The semiquantitative scoring system used is simple and reproducible. Its results correlate well with the quantitative estimates obtained with DCC. The scores can provide an estimate of the level of ER in a given tumour and whether it is absent, low, moderate, high or very high which may be of value to oncologists.

This study was partly supported by a grant from Dako Ltd.

1 Scottish Cancer Trials Breast Group and ICRF Breast Unit, Guy's Hospital, London. Adjuvant ovarian ablation versus $\mathrm{CMF}$ chemotherapy in premenopausal women with pathological stage II breast carcinoma: the Scottish trial. Lancet 1993;341:1293-8.

2 Shintaku IP, Said JW. Detection of estrogen receptors with monoclonal antibodies in routinely processed formalin-fixed paraffin sections of breast carcinoma. Use of DNase pretreatment to enhance sensitivity of the reaction. Am 7 Clin Pathol 1987;87:161-7.

3 Elias JM, Heimann A, Cain T, Margiotta M, Gallery F, Gomes C. Estrogen receptor localization in paraffin sections by enzyme digestion, repeated applications of sections by enzyme digestion, repeated applications of
primary antibody, and imidazole. $₹$ Histotechnol 1990;13:

4 Soomro S, Shousha S, Sinnett HD. Oestrogen and progesterone receptors in screen-detected breast carcinoma: an immunohistological study using paraffin sections. Histopathology 1992;21:543-7.

\title{
Prevalence of Epstein-Barr virus in the cervix
}

\author{
Y Taylor, W T Melvin, H F Sewell, G Flannelly, F Walker
}

\begin{abstract}
Cervical smears from 327 women were examined using the polymerase chain reaction (PCR) targeted to a sequence in the Bam H1 W region of the Epstein-Barr virus (EBV) to determine the prevalence of the virus in the cervix. EBV was detected in 131 (40\%) of the 327 women. Of the 235 women with normal cytology, $98(42 \%)$ were positive. Of the 92 women with dyskariotic smears, 33 (36\%) were positive.
\end{abstract}

(F Clin Pathol 1994;47:92-93)

Department of Pathology, University of Aberdeen Medical School, Aberdeen, AB9 2ZD Y Taylor F Walker

Department of Molecular and Cell Biology

W T Melvin

Department of Obstetrics and Gynaecology G Flannelly

Department of Immunology, University of Nottingham H F Sewell Correspondence to: Professor F Walker

\section{(F Clin Pathol 1994;47:92-93)}

Epstein-Barr virus (EBV) is a human herpes virus which is associated with a variety of neoplasias such as Burkitt's lymphoma and nasopharyngeal carcinoma. The reasons for this association are poorly understood, but the virus can transform cells bearing the $\mathrm{EBV} / \mathrm{C} 3 \mathrm{~d}$ receptor $^{1}$ and make them receptive to other oncogenic events.

In almost all healthy EBV antibody positive people the major site from which the virus is shed is the oropharynx, and viral replication seems to be restricted to squamous epithelial cells. ${ }^{2}$ With the recognition that the uterine cervix is another site where the virus is shed and can replicate, ${ }^{3}$ the role of EBV in cervical neoplasia requires elucidation. As an initial step it was decided to establish if EBV is commonly present in the cervix and whether there is any difference in its prevalence in cytologically normal and cytologically dyskariotic cervices.

\section{Methods}

The study population of 327 was drawn from the Grampian call/recall cervical screening programme. It consisted of 235 women (mean age 33.4, range 17-67 years) with normal cervical smears attending family planning and general practitioner clinics, and 92 women (mean age $31 \cdot 8$, range 18-62 years) with dyskariotic smears attending colposcopy clinics. Ninety of the latter group had confirmation of squamous epithelial abnormalities in biopsy specimens taken subsequent to the smears.

Cervical smears collected with a spatula were collected into phosphate buffered saline and stored at $-20^{\circ} \mathrm{C}$ until DNA extraction. All DNA samples were subjected to an amplification reaction directed to a portion of the $\beta$ globin gene to validate the quality of the extracted DNA. ${ }^{4}$

The polymerase chain reaction (PCR) was targeted to a sequence in the $\operatorname{Bam} \mathrm{H} 1 \mathrm{~W}$ region of the EBV genome. ${ }^{5}$ Reactions were carried out in $50 \mu \mathrm{l}$ volumes containing $50 \mathrm{mM} \mathrm{K} \mathrm{Cl,} 10 \mathrm{mM}$ TRIS-HCl (pH 8.3), $1 \mathrm{mM} \mathrm{Mg} \mathrm{Cl}, 0.01 \%$ gelatine, $200 \mu \mathrm{M}$ each dNTP (dATP, dGTP, dCTP and dTTP), 